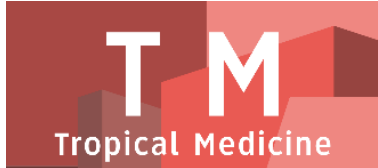

PAPER - OPEN ACCESS

\title{
Pengujian Sifat Fisik dan Aktivitas Antibakteri Sediaan Gel Hand Sanitizer Ekstrak Daun Lidah Mertua (Sansevieria trifasciata Prain)
}
Author
: Setyo Nurwaini
DOI
: 10.32734/tm.v1i3.266
Electronic ISSN
: 2623-0542
Print ISSN
: 2623-0550

Volume 1 Issue 3 - 2018 TALENTA Conference Series: Tropical Medicine (TM)

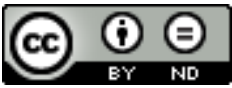

This work is licensed under a Creative Commons Attribution-NoDerivatives 4.0 International License.

Published under licence by TALENTA Publisher, Universitas Sumatera Utara
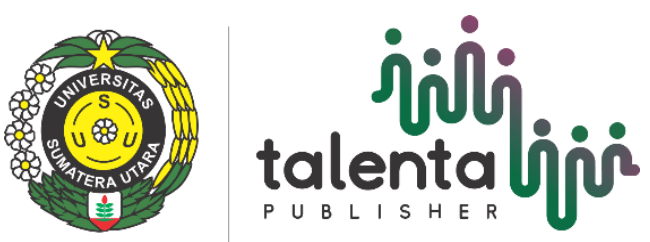


\section{ก่نำ \\ talentaliọi}

\title{
Pengujian Sifat Fisik dan Aktivitas Antibakteri Sediaan Gel Hand Sanitizer Ekstrak Daun Lidah Mertua (Sansevieria trifasciata Prain)
}

\author{
Setyo Nurwaini ${ }^{\mathrm{a}^{*}}$, Intan Dewi Saputri ${ }^{\mathrm{b}}$ \\ ${ }^{a b}$ Laboratorium Farmasetika, FakultasFarmasi, Universitas Muhammadiyah Surakarta, Surakarta, 57162
}

setyo.nurwaini@ums.ac.id

\begin{abstract}
Abstrak
Daun Lidah mertua (Sansevieria trifasciata Prain) diketahui mengandung senyawa polifenol, flavonoid dan saponin yang merupakan agen antibakteri. Lidah mertua memiliki aktivitas antibakteri terhadap Staphylococcus aureus dan Escherichia coli. Penelitian ini bertujuan untuk mengetahui konsentrasi ekstrak daun lidah mertua dalam sediaan gel yang memiliki aktivitas antibakteri terbesar dalam penurunan jumlah angka kuman. Ekstraksi daun lidah mertua menggunakan metode maserasi dengan pelarut etanol 96\%. Variasi konsentrasi ekstrak daun lidah mertua dalam sediaan gel hand sanitizer yang digunakan yaitu F1 (10\%), F2 (15\%) dan F3 (20\%). Na CMC digunakan sebagai gelling agent dalam formulasi. Sediaan gel hand sanitizer daun lidah mertua diuji aktivitas antibakteri terhadap Escherichia coli menggunakan metode difusi sumuran, sifat fisik (organoleptik, homogenitas, $\mathrm{pH}$, viskositas, daya sebar dan daya lekat) serta penurunan jumlah angka kuman dengan metode swabbing. Hasil uji aktivitas antibakteri gel hand sanitizer ekstrak daun lidah mertua memiliki zona hambat bakteri terhadap Escherichia coli pada F1, F2 dan F3 berturut-turut sebesar 7,33 mm, 8,67 mm dan 9,75 mm. Hasil evaluasi sifat fisik gel daun lidah mertua memenuhi kriteria gel yang baik, namun memiliki daya lekat kurang 1 detik. Hasil penurunan jumlah angka kuman gel hand sanitizer daun lidah mertua paling besar pada F3 sebesar 52\%. Namun, analisa statistik dengan Anova One Way menunjukkan bahwa F1 (32\%), F2 (35\%) dan F3 (52\%) tidak menunjukkan perbedaan yang signifikan dalam penurunan jumlah angka kuman. Berdasarkan hasil penelitian ini dapat disimpulkan gel hand sanitizer ekstrak daun lidah mertua memiliki kemampuan dalam menurunkan angka kuman dan dapat digunakan sebagai alternatif sebagai sediaan gel hand sanitizer.
\end{abstract}

Kata kunci: Sansevieria trifasciata Prain, antibakteri, gel hand sanitizer

\begin{abstract}
Sansevieria trifasciata Prain leaf is known contains polyphenolic, flavonoids and saponins compounds which are antibacterial agents. Sansevieria trifasciata Prain leaf has antibacterial activity against Staphylococcus aureus and Escherichia coli. The aim of this study is to determine the concentration of Sansevieria leaves extracts in hand sanitizer gel preparations that have the greatest antibacterial activity based on the decrease of the number of germs. Sansevieria trifasciata Prain leaves was extracted using maceration method with $96 \%$ ethanol solvent. Variation of concentration of Sansevieria extract in hand sanitizer gel used were F1 (10\%), F2 (15\%) and F3 (20\%). Na CMC was used as a gelling agent. Hand sanitizer gel of Sansevieria leaves extracts were tested antibacterial activity against Escherichia coli using well diffusion method, physical properties (organoleptic, homogeneity, $\mathrm{pH}$, viscosity, spreadability and stickiness) and decreasing number of germs by swabbing method. The result showed hand sanitizer gel of Sansevieria trifasciata Prain leaf extract had zone of inhibition on Escherichia coli from F1 to F3 are $7.33 \mathrm{~mm}, 8.67 \mathrm{~mm}$ and $9.75 \mathrm{~mm}$. Physical properties evaluations of hand sanitizer gel met criteria of a good gel, although has stickiness less than 1 second. F3 had the highest activity in decreasing the number of germs approximately 52\%. However, statistical analysis showed that F1 (32\%), F2 (35\%) and F3 (52\%) had no significant difference in decreasing the number of germs. Based on the results of this study, it can be concluded that Sansevieria trifasciata Prain leaf extract hand sanitizer gel has ability in lowering the number of germs and could be used as an alternative as hand santitizer gel preparations.
\end{abstract}

Keywords: Sansevieria trifasciata Prain, antibacterial, hand sanitizer gel

\section{Pendahuluan}

Kuman dapat masuk ke dalam mulut melalui makanan, air dan tangan yang kotor sehingga menyebabkan berbagai jenis penyakit bahkan kematian pada anak balita. Kuman banyak yang berasal dari kotoran manusia dan binatang. Buruknya kebersihan perorangan dan kesehatan lingkungan termasuk langkanya persediaan air bersih, mengakibatkan $88 \%$ kematian anak di seluruh dunia karena diare, hampir $90 \%$ di antaranya anak balita [1]. 
Telapak tangan merupakan bagian tubuh yang paling sering terkena kontak dengan mikroorganisme karena sering digunakan untuk beraktivitas. Berdasarkan penelitian, tidak mencuci tangan dapat meningkatkan risiko menderita diare sebesar 95\%, sedangkan mencuci tangan dengan sabun dapat menurunkan risiko menderita penyakit diare sebesar $4 \%$. Sehingga ada keterkaitan antara perilaku mencuci tangan dengan sabun dan penyakit diare [2]

Penggunaan hand sanitizer dikatakan lebih efektif membunuh kuman dengan waktu yang singkat dibandingkan mencuci tangan dengan air mengalir, karena di dalam air mengalir tidak terdapat zat anti kuman (antibakteri). Selain itu, kuman bisa saja terbawa bersama air mengalir yang menyebabkan penurunan jumlah kuman tidak efektif [3]. Namun hand sanitizer mempunyai kekurangan yaitu bisa mengiritasi kulit serta membuat kulit menjadi kering [4]. Dengan alasan tersebut maka dibuat inovasi hand sanitizer dari bahan alami yang lebih aman dan berkhasiat antibakteri tetapi tidak mengiritasi kulit.

Salah satu tanaman yang berkhasiat antibakteri adalah ekstrak etanol daun lidah mertua (Sansevieria trifasciata Prain) yang memiliki kandungan senyawa polifenol, saponin, dan flavonoid yang bekerja sebagai antibakteri. Hasil skrining antibakterial dari daun lidah mertua (Sansevieria trifasciata Prain) menunjukkan bahwa senyawa yang terkandung dalam daun tersebut mempunyai aktivitas antibakteri terhadap Gram positif Staphylococcus aureus dan Gram negatif Pseudomonas aeruginosa dan Escherichia coli [5].

Produk pembersih tangan di pasaran pada umumnya berupa gel. Gel merupakan sediaan semisolid yang dapat memberikan sensasi lembut dan nyaman digunakan untuk sediaan topikal. Gelling agent digunakan sebagai basis dalam penyusun konsistensi sediaan gel, salah satunya Na-CMC untuk meningkatkan viskositas dalam formulasi sediaan oral dan topikal. Na-CMC dengan konsentrasi 3-6\% digunakan untuk menghasilkan gel serta digunakan sebagai basis pembuatan pasta [6]. Sediaan gel ekstrak daun cocor bebek dengan basis Na-CMC memberikan susunan formula yang homogen serta pH Na-CMC sebesar 6 yang masuk rentang $\mathrm{pH}$ kulit yaitu 4,5-7,0 sehingga basis gel Na-CMC tidak mengiritasi kulit [7].

Berdasarkan latar belakang di atas, penelitian ini dilakukan untuk mengetahui aktivitas antibakteri terbesar dalam gel ekstrak daun lidah mertua terhadap jumlah angka kuman sebagai inovasi pada formulasi gel hand santitizer.

\section{Bahan dan Metode}

Tanaman lidah mertua diperoleh dari Desa Kalisoro, Tawangmangu, Kabupaten Karanganyar, Jawa Tengah, etanol 96\% (PT. Seino Era Nusa), Escherichia coli $\left(\right.$ ATCC $\left.^{\circledR} 25922^{\mathrm{TM}}\right)$, paper blank disc $\left(\right.$ Oxoid $\left.^{\circledR}\right)$, media Brain Heart Infusion $\left(\right.$ Onemed $\left.^{\circledR}\right)$, media Mueller Hinton Agar (E. Merck $\left.{ }^{\circledR}\right)$, blue tip dan yellow tip $\left(\right.$ Onemed $\left.^{\circledR}\right)$, hand sanitizer Value Plus ${ }^{\circledR}$, larutan $\mathrm{NaCl} 0,9$ (E. Merck ${ }^{\circledR}$ ), $\mathrm{Na} \mathrm{CMC} \mathrm{(Brataco}{ }^{\circledR}$ ), gliserin (CV. Cipta Kimia), propilenglikol (CV. Cipta Kimia), metil paraben teknis.

Daun lidah mertua yang masih segar disortasi basah, kemudian dicuci dengan air mengalir hingga bersih. Daun lidah mertua yang telah disortasi basah kemudian dipotong kecil-kecil dan dikeringkan dengan cara dijemur di bawah sinar matahari dan di atasnya ditutup menggunakan kain hitam. Daun lidah mertua yang telah kering kemudian disortasi kering dan siap untuk dilakukan ekstraksi.

Maserasi dilakukan dengan menimbang \pm 600 gram simplisia daun lidah mertua, kemudian direndam dalam 4,2 liter etanol 96\% didiamkan selama 4 hari sambil diaduk sesekali. Hasil maserasi simplisia daun lidah mertua kemudian disaring agar cairan etanol dan ampasnya terpisah. Ekstrak cair kemudian diuapkan menggunakan alat rotary evaporator pada suhu $60^{\circ} \mathrm{C}$ dengan kecepatan 90 rpm, kemudian diuapkan kembali di waterbath hingga mendapat ekstrak kental [8].

Ekstrak kental yang telah diperoleh kemudian dibuat variasi konsentrasi ekstrak yang berbeda yaitu 10\%, 15\% dan 20\%. Cara pembuatan gel hand sanitizer dengan basis Na CMC [9] yaitu dengan melarutkan ekstrak etanol daun lidah mertua dalam sebagian akuades pada masing-masing konsentrasi. Na CMC ditambahkan dalam akuades panas sebanyak 20 kali dari berat Na CMC dan didiamkan selama \pm 15 menit, diaduk hingga terbentuk massa gel yang homogen. Propilenglikol, gliserin dan metil paraben dimasukkan ke dalam basis gel kemudian diaduk hingga homogen. Langkah terakhir yaitu menambahkan ekstrak daun lidah mertua dan sisa akuades lalu diaduk hingga semua bahan homogen. Formula sediaan gel hand sanitizer yang dibuat dalam berbagai konsentrasi ekstrak [10] (Tabel 1

Tabel 1).

Tabel 1. Formulasi Sediaan Gel Hand Sanitizer Ekstrak Daun Lidah Mertua

\begin{tabular}{lccc}
\hline \multicolumn{1}{c}{ Bahan } & \multicolumn{3}{c}{ Konsentrasi (\% b/v) } \\
\cline { 2 - 4 } Ekstrak daun lidah mertua & F1 & F2 & F3 \\
CMC-Na & 10 & 15 & 20 \\
Gliserin & 2 & 10 & 10 \\
Propilenglikol & 10 & 5 & 5 \\
Metil paraben & 5 & 0,2 & 0,2 \\
Akuades (hingga) & 0,2 & 100 & 100 \\
\hline
\end{tabular}




\section{Uji organoleptik}

Pengamatan fisik sediaan gel hand sanitizer ekstrak daun lidah mertua meliputi bau, warna dan homogenitas sediaan. Sediaan gel yang baik yaitu jernih dengan konsistensi setengah padat [11].

\section{Uji homogenitas}

Uji homogenitas dilakukan untuk mengetahui apakah sediaan gel yang dibuat homogen atau tidak, dengan cara mendispersikan gel sebanyak $500 \mathrm{mg}$ di atas kaca objek. Sediaan harus menunjukkan susunan yang homogen dan tidak terlihat adanya butiran kasar [12].

\section{Uji viskositas}

Uji viskositas dilakukan menggunakan alat Viscometer Rion seri VT 04 dengan mencelupkan rotor no 2 ke dalam sediaan gel.

\section{Uji $p H$}

Uji pH sediaan gel menggunakan $\mathrm{pH}$ meter. Elektroda $\mathrm{pH}$ meter dicelupkan ke dalam sediaan uji pada masing-masing konsentrasi sampai pH meter menunjukkan pembacaan yang tetap [13].

\section{Uji daya sebar}

Sediaan hasil formulasi ditimbang sebanyak $500 \mathrm{mg}$ dan diletakkan di tengah cawan Petri yang sebelumnya pada bagian dalam telah ditempeli kertas milimeter blok lalu ditutup dengan cawan petri lain. Masing-masing beban seberat $50 \mathrm{~g}, 100 \mathrm{~g}$ dan $150 \mathrm{~g}$ ditambahkan, didiamkan selama 1 menit lalu diukur dan dicatat diameter penyebaran gel. Uji ini dilakukan setelah 48 jam waktu pembuatan sediaan [14].

\section{Uji daya lekat}

Uji ini dilakukan dengan mengambil gel sebanyak $500 \mathrm{mg}$ diletakkan di atas object glass dan ditempelkan pada object glass yang lain lalu ditekan dengan beban $1 \mathrm{~kg}$ selama 5 menit. Object glass dipasang pada alat tes dan dilepaskan beban seberat 80 gram. Waktu yang dibutuhkan hingga object glass terlepas dicatat dalam detik.

\section{Uji aktivitas antibakteri ekstrak etanol daun lidah mertua}

Uji aktivitas antibakteri ekstrak etanol daun lidah mertua dilakukan menggunakan metode disc plate. Ekstrak etanol daun lidah mertua sebanyak $30 \mu \mathrm{L}$ diteteskan ke paper disc dan ditunggu sampai etanol menguap. Kontrol negatif menggunakan etanol $96 \%$ diambil sebanyak $30 \mu \mathrm{L}$ lalu diteteskan ke paper disc. Setelah etanol menguap, paper disc diletakkan di atas media yang mengandung kultur bakteri Escherichia coli. Media kemudian diinkubasi pada suhu $37^{\circ} \mathrm{C}$ selama 24 jam kemudian diukur zona hambatnya [15]. Data hasil uji aktivitas antibakteri ekstrak etanol daun lidah mertua dihitung secara statistik menggunakan Anova One Way untuk mengetahui pengaruh variasi konsentrasi ekstrak terhadap aktivitas antibakteri.

\section{Uji aktivitas antibakteri sediaan gel ekstrak daun lidah mertua terhadap E.coli.}

Uji aktivitas antibakteri gel hand sanitizer daun lidah mertua dilakukan menggunakan metode difusi sumuran. Media yang mengandung kultur bakteri Escherichia coli dilubangi menggunakan cork borer nomor 3 dengan diameter 6 mm, kemudian masing-masing konsentrasi gel hand sanitizer daun lidah mertua diletakkan sesuai lubang pada media. Kontrol negatif yang digunakan adalah gel tanpa ekstrak dan kontrol positifnya sediaan hand sanitizer yang ada di pasaran (Value Plus ${ }^{\circledR}$ ). Media kemudian diinkubasi pada suhu $37^{\circ} \mathrm{C}$ selama 24 jam kemudian diukur zona hambatnya [15].

\section{Uji penurunan angka kuman.}

Uji penurunan angka kuman dilakukan untuk mengetahui jumlah koloni kuman pada telapak tangan. Metode yang digunakan yaitu swabbing dengan jumlah responden 3 orang untuk setiap formula. Data yang diperoleh berupa jumlah koloni bakteri yang tumbuh pada media MH agar sebelum dan sesudah menggunakan gel hand sanitizer daun lidah mertua. Sampel kuman diambil dengan mengusap lidi steril yang telah dicelupkan dalam larutan $\mathrm{NaCl}$ ke telapak tangan kiri sebelum dan sesudah menggunakan gel hand sanitizer daun lidah mertua kemudian diinokulasikan pada media Mueller Hinton. Setelah mencuci tangan dengan air, swabbing dilakukan dengan mengusapkan lidi steril pada jari telunjuk dan jari manis secara terpisah sebanyak 2-3 kali kemudian diinokulasikan ke media agar MH. Tahap tersebut diulangi pada jari tengah dan jari kelingking setelah 1 menit menggunakan gel hand sanitizer daun lidah mertua maupun Value Plus ${ }^{\circledR}$. Media agar $\mathrm{MH}$ diinkubasi pada suhu $37^{\circ} \mathrm{C}$ selama 24 jam kemudian dihitung jumlah angka kuman pada media.

\section{Hasil dan Pembahasan}


Daun lidah mertua yang telah diekstrak diperoleh hasil rendemen ekstrak sebesar 13,47\%. Ekstrak kental daun lidah mertua berwarna hijau pekat, berbau khas dan mempunyai tekstur yang kental.

Tabel 2. Hasil Uji Karakteristik Gel Hand Sanitizer Ekstrak Daun Lidah Mertua

\begin{tabular}{|c|c|c|c|}
\hline \multirow{2}{*}{ Karakteristik } & \multicolumn{3}{|c|}{ Formula } \\
\hline & F1 $(n=3)$ & $\mathrm{F} 2(\mathrm{n}=3)$ & $\mathrm{F} 3(\mathrm{n}=3)$ \\
\hline $\mathrm{Bau}$ & Khas & Khas & Khas \\
\hline Homogenitas & Homogen & Homogen & Homogen \\
\hline $\mathrm{pH}$ & $4,62 \pm 0,06$ & $4,40 \pm 0,04$ & $4,25 \pm 0,06$ \\
\hline Daya sebar $\left(\mathrm{cm}^{2}\right)$ & $12,19 \pm 1,57$ & $11,86 \pm 0,70$ & $16,40 \pm 3,57$ \\
\hline Daya lekat (detik) & 0,47 & 0,47 & 0,83 \\
\hline
\end{tabular}

Hasil pengamatan dari uji ini dilihat secara visual warna, bau serta homogenitasnya. Gel dengan konsentrasi $10 \%$ berwarna hijau, sedangkan pada konsentrasi $15 \%$ dan $20 \%$ berwarna hijau pekat (Tabel 2). Perbedaan ini disebabkan karena formula dari masing-masing konsentrasi yang berbeda. Bentuk dari sediaan gel ini pada konsentrasi $10 \%$ tidak terlalu kental karena kandungan air yang lebih banyak, sedangkan pada konsentrasi 15\% dan 20\% semakin mengental karena jumlah air lebih sedikit. Bau dari ketiga variasi sediaan gel hand sanitizer ini beraroma khas daun lidah mertua. Uji homogenitas dilakukan untuk mengetahui apakah sediaan gel yang dibuat homogen atau tidak. Hasil pengamatan yang diperoleh bahwa ketiga gel dengan variasi yang beragam hasilnya homogen karena tidak terdapat butiran kasar pada saat didispersikan di kaca obyek (Tabel 2). Hal tersebut menunjukkan bahwa semua bahan yang diformulasi bercampur dengan baik tanpa adanya butiran kasar [16].

Uji pH dilakukan untuk mengetahui apakah $\mathrm{pH}$ dari sediaan gel ekstrak daun lidah mertua masuk dalam rentang $\mathrm{pH}$ kulit. $\mathrm{pH}$ kulit yang normal dalam rentang 4-6 agar tidak menyebabkan iritasi kulit [17]. Hasil pengamatan yang diperoleh dari ketiga variasi formula gel daun lidah mertua bahwa ketiganya masuk dalam rentang $\mathrm{pH}$ kulit, sehingga gel hand sanitizer daun lidah mertua dapat diterima karena tidak menyebabkan iritasi pada kulit. Data yang diperoleh kemudian dihitung secara statistik menggunakan Anova One Way untuk mengetahui pengaruh konsentrasi ekstrak terhadap nilai pH gel hand sanitizer daun lidah mertua. Hasil yang diperoleh menunjukkan bahwa $\mathrm{p}<0,05$ yang artinya perbedaan konsentrasi ekstrak mempengaruhi nilai $\mathrm{pH}$

sediaan. Hal tersebut ditunjukkan bahwa setiap penambahan konsentrasi ekstrak, gel hand sanitizer daun lidah mertua mengalami penurunan $\mathrm{pH}$ (Gambar 1

Gambar 1). Penurunan $\mathrm{pH}$ disebabkan karena adanya senyawa flavonoid yang terkandung pada daun lidah mertua yang bersifat agak asam [18]. Sedangkan pH yang dimiliki Na-CMC lebih tinggi yaitu 6,5-8, [19].

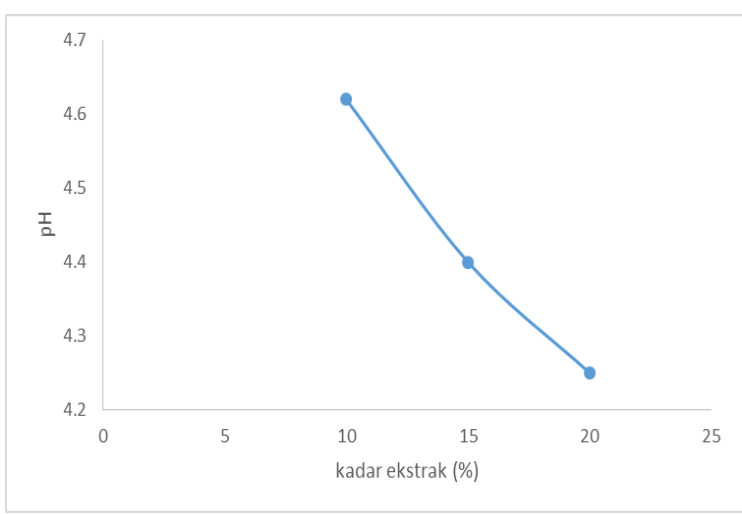

(a)

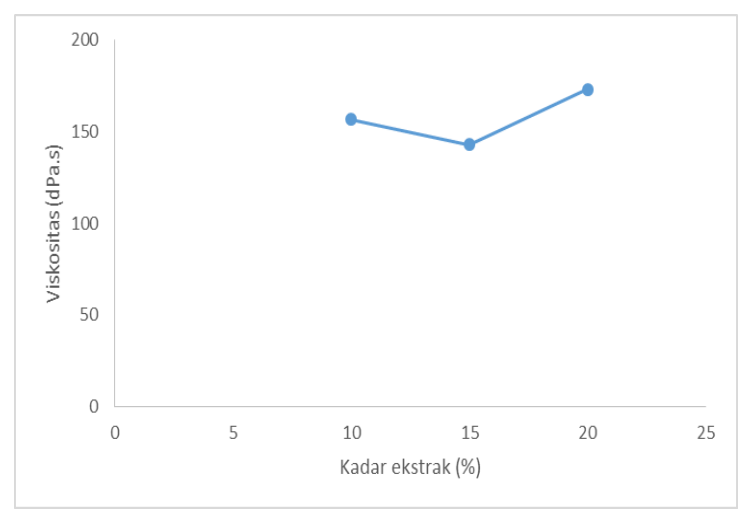

(b)

Gambar 1. Profil pH (a) dan Profil Viskositas Gel Hand Sanitizer Ekstrak Daun Lidah Mertua (b).

Uji viskositas dilakukan untuk mengetahui kekentalan dari sediaan gel dan ketahanan gel untuk mengalir pada berbagai variasi konsentrasi ekstrak. Gel dikatakan baik apabila memiliki viskositas dalam rentang 50-1000 dPa.s agar mudah dikeluarkan dari tube/wadah serta memudahkan dalam pengaplikasian [20]. Hasil uji viskositas sediaan gel ekstrak daun lidah mertua pada semua variasi konsentrasi masuk dalam rentang viskositas tersebut yang ditunjukkan pada Tabel 2. Nilai viskositas semakin meningkat dengan kenaikan konsentrasi ekstrak daun lidah mertua (Gambar 1). Na CMC mempunyai kelebihan untuk meningkatkan viskositas gel karena pada saat $\mathrm{Na} \mathrm{CMC}$ dicampur dengan air, maka $\mathrm{Na}^{+}$akan lepas kemudian diganti dengan ion $\mathrm{H}^{+}$yang akan membentuk HCMC [21]. Nilai viskositas dari sediaan gel hand sanitizer daun lidah mertua ini dipengaruhi oleh perbedaan konsentrasi ekstrak yang ditunjukkan dengan nilai $\mathrm{p}<0,05$. Peningkatan viskositas disebabkan oleh penambahan konsentrasi ekstrak yang menyebabkan sediaan gel hand sanitizer menjadi lebih kental karena semakin tinggi konsentrasi ekstrak maka kandungan airnya akan lebih sedikit. 
Uji daya sebar bertujuan untuk mengetahui daya penyebaran gel pada permukaan kulit sehingga diketahui penyebaran zat aktif dari sediaan gel ekstrak daun lidah mertua. Pada penelitian lain [22] yang menggunakan basis Na CMC 2\%, daya sebar yang dihasilkan yaitu $12-15 \mathrm{~cm}$. Daya sebar sediaan gel ekstrak daun lidah mertua dengan basis Na CMC $2 \%$ dengan variasi konsentrasi $10 \%$ dan $15 \%$ tidak berbeda jauh, tetapi pada konsentrasi $20 \%$ menunjukkan perbedaan dari konsentrasi yang lain.

Dari perbedaan tersebut kemudian dihitung menggunakan uji statistik Anova One Way untuk memastikan apakah perbedaan konsentrasi berpengaruh terhadap daya sebar sediaan. Dari hasil statistik yang diperoleh menunjukkan bahwa $\mathrm{p}>0,05$ yang artinya nilai daya sebar dari sediaan gel hand sanitizer daun lidah mertua tidak dipengaruhi perbedaan konsentrasi ekstrak. Daya sebar yang besar disebabkan oleh konsentrasi propilenglikol yang lebih tinggi daripada konsentrasi Na CMC [23]. Daya sebar yang besar akan membuat gel hand sanitizer semakin mudah menyebar di kulit serta zat aktif yang terkandung di dalam basis gel akan menyebar lebih merata sehingga efek antibakteri dari ekstrak daun lidah mertua akan lebih optimal [24].

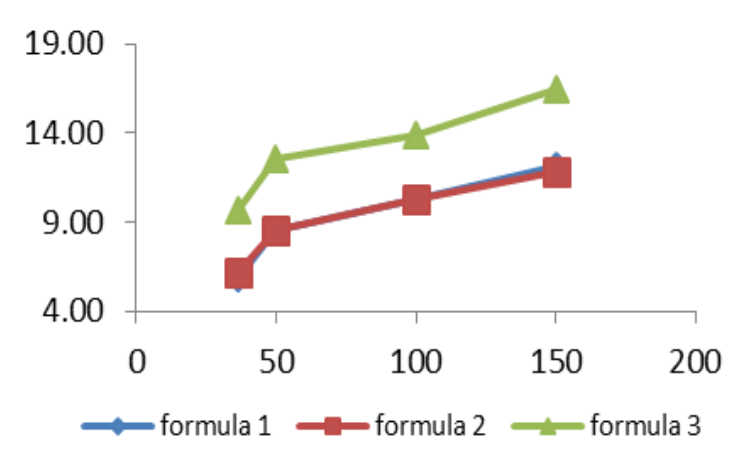

(a)

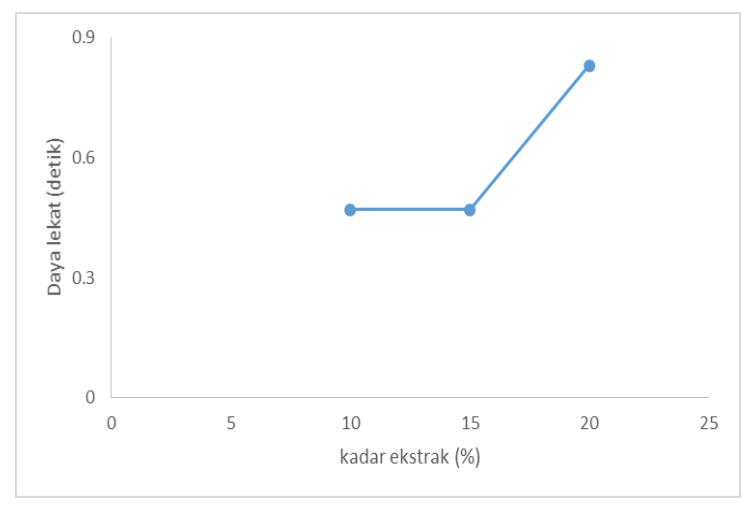

(b)

Gambar 2. Profil Daya Sebar (a) dan Daya Lekat Gel Hand Sanitizer Ekstrak Daun Lidah Mertua (b).

Uji daya lekat dimaksudkan untuk mengetahui kemampuan gel melekat di permukaan kulit dalam waktu yang cukup lama sebelum sediaan dicuci atau dibersihkan. Daya lekat gel yang baik adalah lebih dari 1 detik [11]. Daya lekat yang baik memungkinkan zat antibakteri dalam gel melekat pada permukaan kulit, sehingga menghasilkan efek yang diinginkan. Hasil dari ketiga variasi konsentrasi dari formula gel daun lidah mertua menunjukkan bahwa daya lekat gel tersebut kurang baik karena kurang 1 detik. Hal ini menyebabkan sediaan gel hand sanitizer ekstrak daun lidah mertua tidak melekat sempurna di permukaan kulit. Dari hasil statistik yang diperoleh, daya lekat dipengaruhi oleh peningkatan konsentrasi ekstrak daun lidah mertua dalam sediaan gel hand sanitizer $(\mathrm{p}<0,05)$. Konsentrasi ekstrak yang meningkat akan membuat nilai daya lekat mengalami kenaikan (Gambar 2). Konsentrasi ekstrak yang meningkat membuat air yang ditambahkan semakin sedikit, hal itu membuat formula menjadi lebih kental dan viskositasnya meningkat sehingga gel hand sanitizer akan lebih lama menempel di kulit.

Uji pendahuluan ekstrak etanol daun lidah mertua dilakukan sebelum uji antibakteri sediaan gel hand sanitizer untuk mengetahui apakah ekstrak etanol daun lidah mertua mempunyai aktivitas antibakteri terhadap Escherichia coli. Sensitifitas bakteri uji terhadap ekstrak etanol daun lidah mertua dilihat dari terbentuknya zona bening di sekitar paper disc atau sumuran yang menunjukkan bahwa pertumbuhan bakteri E. coli dapat dihambat oleh zat antibakteri dari daun lidah mertua (Gambar 3 dan Gambar 4). Hasil uji aktivitas antibakteri ekstrak daun lidah mertua sebelum dan sesudah diformulasi menjadi gel hand sanitizer dapat dilihat pada Tabel 3 .

Tabel 3. Hasil Uji Aktivitas Antibakteri Ekstrak Dan Gel Hand Sanitizer Ekstrak Daun Lidah Mertua Terhadap Eschericia coli

\begin{tabular}{|c|c|c|c|}
\hline \multicolumn{4}{|c|}{ Rerata diameter zona hambat $(\mathrm{mm})(\mathrm{n}=3)$} \\
\hline & $10 \%$ & $15 \%$ & $20 \%$ \\
\hline Esktrak* & $8,67 \pm 0,3$ & $9,83 \pm 0,6$ & $12,50 \pm 2,2$ \\
\hline Gel Hand Sanitizer** & $7,33 \pm 0,6$ & $8,67 \pm 1,0$ & $9,75 \pm 0,3$ \\
\hline
\end{tabular}

*Sebelum Diformulasi (Diameter Disc 6mm)

**Setelah Diformulasi (Diameter Sumuran 6mm) 


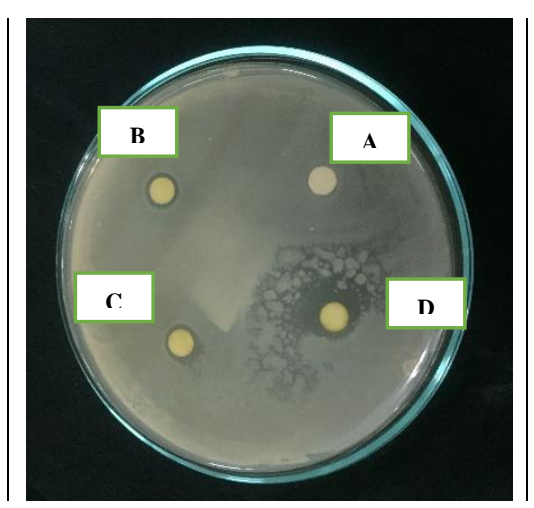

Gambar 3. Hasil Uji Disk Plate Ekstrak Daun Lidah Mertua Terhadap E. coli. Keterangan sampel: kontrol negatif etanol $96 \%$ (A), konsentrasi ekstrak daun lidah mertua 10\% (B), konsentrasi ekstrak daun lidah mertua 15\% (C) dan konsentrasi ekstrak daun lidah mertua $20 \%$ (D).

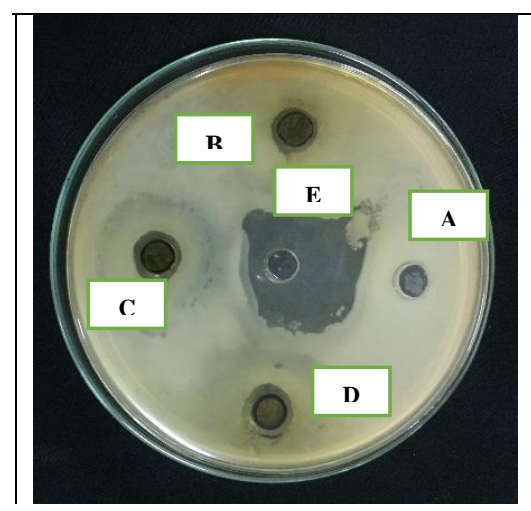

Gambar 4. Hasil Uji Sumuran Gel Ekstrakdaun Lidah Mertua Terhadap E. coli. Keterangan sampel: kontrol negatif gel basis Na CMC (A), konsentrasi gel ekstrak daun lidah mertua 10\% (B), konsentrasi gel ekstrak daun lidah mertua 15\% (C), konsentrasi gel ekstrak daun lidah mertua 20\% (D) dan kontrol positif Value Plus® (E).

Data yang telah diperoleh kemudian diuji menggunakan Anova One Way untuk mengetahui pengaruh variasi konsentrasi ekstrak terhadap aktivitas antibakteri ekstrak daun lidah mertua. Hasil statistik yang diperoleh menunjukkan bahwa terdapat perbedaan yang signifikan dari variasi konsentrasi ekstrak maupun gel hand sanitizer daun lidah mertua terhadap aktivitas antibakteri $(\mathrm{p}<0,05)$. Selain itu, dilakukan uji t berpasangan untuk mengetahui perbedaan ekstrak daun lidah mertua sebelum dan sesudah diformulasi terhadap aktivitas antibakteri. Hasil yang diperoleh dari ketiga konsentrasi ekstrak daun lidah mertua tidak ada perbedaan yang signifikan sebelum dan sesudah diformulasi menjadi gel hand sanitizer ( $\mathrm{p}>0,05$ ). Maka dapat disimpulkan bahwa formulasi gel hand sanitizer dengan basis Na-CMC tidak mempengaruhi aktivitas antibakteri ekstrak daun lidah mertua.

Penurunan jumlah koloni kuman pada telapak tangan setelah menggunakan gel hand sanitizer daun lidah mertua dihitung menggunakan metode replika [25]. Uji replika bertujuan untuk mengetahui seberapa besar penurunan jumlah koloni kuman pada telapak tangan sebelum dan sesudah menggunakan gel hand sanitizer ekstrak daun lidah mertua maupun sediaan yang ada di pasaran sebagai kontrol positif (Gambar 5). Penurunan jumlah koloni kuman pada telapak tangan dapat dilihat pada Tabel 4.

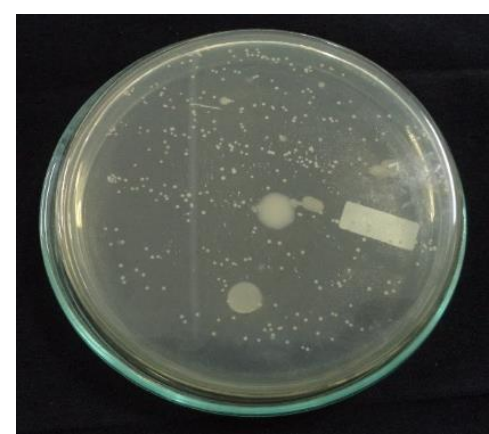

(A)

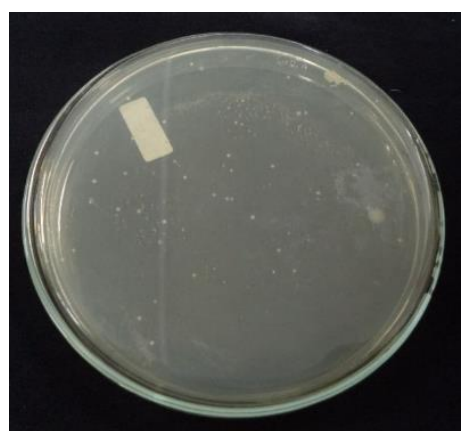

(B)

Gambar 5. Hasil Uji Swab Sebelum (A) Dan Sesudah Menggunakan Gel Hand Sanitizer Ekstrak Lidah Mertua.(B) 
Tabel 4. Hasil Uji Penurunan Angka Kuman Gel Hand Sanitizer Ekstrak Daun Lidah Mertua

\begin{tabular}{cc} 
Sediaan & Rerata penurunan bakteri $(\%) \pm \mathrm{SD}(\mathrm{n}=3)$ \\
\hline Kontrol $(+)$ & $57 \% \pm 0,07$ \\
$10 \%$ & $32 \% \pm 0,23$ \\
$15 \%$ & $35 \% \pm 0,25$ \\
$20 \%$ & $52 \% \pm 0,16$ \\
\hline
\end{tabular}

Hasil rata-rata penurunan angka kuman ditunjukkan pada Tabel 4 
Tabel 4 bahwa penurunan jumlah angka kuman terbesar pada konsentrasi 20\% yaitu sebesar 52\%. Hasil yang telah diperoleh selanjutnya diuji secara statistik dengan uji Anova One Way untuk melihat perbedaan penurunan jumlah koloni dalam variasi konsentrasi yang berbeda sebelum dan setelah penggunaan gel hand sanitizer ekstrak daun lidah mertua. Hasil yang diperoleh pada konsentrasi yang meningkat menunjukkan penurunan jumlah angka kuman yang meningkat pula. Hasil tersebut kemudian dihitung menggunakan uji statistik Anova One Way yang menunjukkan hasil yang tidak signifikan ( $p>0,05)$, artinya perbedaan konsentrasi tidak berpengaruh pada penurunan jumlah angka kuman sebelum dan sesudah menggunakan sediaan gel hand sanitizer ekstrak daun lidah mertua secara signifikan. Sedangkan pada uji t berpasangan tidak menunjukkan perbedaan yang signifikan. Hasil uji t berpasangan menunjukkan nilai t hitung masing masing variabel lebih besar dari t tabel, yang berarti tidak ada perbedaan yang signifikan sebelum dan sesudah penggunaan gel hand sanitizer.

\section{Kesimpulan}

Berdasarkan penelitian yang telah dilakukan, dapat diambil kesimpulan:

a. Ekstrak daun lidah mertua sebelum dan sesudah diformulasi mempunyai aktivitas antibakteri yang sama.

b. Penurunan jumlah angka kuman hand gel daun lidah mertua paling besar pada gel dengan konsentrasi ekstrak $20 \%$ yaitu sebesar $52 \%$.

c. Gel hand sanitizer daun lidah mertua memiliki kriteria gel yang baik, namun daya lekat kurang dari 1 detik.

\section{Ucapan Terima Kasih}

Penulis menyampaikan terimakasih kepada LPPM Universitas Muhammadiyah Surakarta yang telah mendanai penelitian ini.

\section{Daftar Pustaka}

[1] Kementerian Kesehatan. (2010). Penuntun Hidup Sehat. UNICEF, Jakarta.

[2] Kementerian Kesehatan RI. (2014). Perilaku Mencuci Tangan Pakai Sabun di Indonesia. UNICEF, Jakarta

[3] Desiyanto, F.A., dan Djanah, S.N. (2013). Efektivitas Mencuci Tangan Menggunakan Cairan Pembersih Tangan Antiseptik (Hand sanitizer) Terhadap Jumlah Angka Kuman. Kesmas, 7 (2). p55-112.

[4] WHO. (2005). The Global Patient Safety Challenge 2005-2006: Clean Care is Safer Care. World Health Organization. p1-25.

[5] Lombogia B., Budiarso F., dan Bodhi W. (2016). Uji Daya Hambat Ekstrak Daun Lidah Mertua (Sansevieria trifasciata folium) Terhadap Pertumbuhan Bakteri Escherichia coli dan Streptococcus sp. Skripsi. Fakultas Kedokteran, Universitas Sam Ratulangi, Manado.

[6] Rowe R.C., Sheskey P.J. dan Quinn M.E. (2009). Handbook of Pharmaceutical Excipients, Sixth edition. Pharmaceutical Press and American Pharmacists Association, Washington, DC.

[7] Istiana S. (2016). Formulasi Sediaan Gel Basis Na-CMC Ekstrak Etanol Daun Cocor Bebek (Kalanchoe pinnata (Lmk.) Pers.) sebagai Penyembuh Luka Bakar pada Kelinci. Skripsi. Fakultas Farmasi, Universitas Muhammadiyah Surakarta, Surakarta.

[8] Ekananda M.A., Dwyana Z., Tambaru E. dan Rante H. (2016). Uji Aktivitas Ekstrak Daun Jambu Biji Psidium guajava L. Dalam Sediaan Gel Hand Sanitizer Terhadap Bakteri Escherichia coli dan Staphylococcus aureus. Repository UNHAS.

[9] Milala A.S., Sofyan M. dan Wahjudi M. (2014) The Formulation and Antibacterial Activity of Hand Sanitizer Gels Containing Lampes (Ocimum sanctum L.) Leaves Extract as An Active Compound. Inatradmed.

[10] Maswadeh H.M., Semreen M.H. dan Naddaf A.R. (2006). Anti-Inflammatory Activity of Achillea and Ruscus Topical Gel on Carrageenan-Induced Paw Edema in Rats. Polish Pharmaceutical Society, 63 (4). p277-280.

[11] Ansel H. (2008). Pengantar Bentuk Sediaan Farmasi, Edisi 4. UI Press, Jakarta.

[12] Ditjen POM. (1985). Formularium Kosmetika Indonesia. Departemen Kesehatan RI, Jakarta.

[13] Badan Standarisasi Nasional. (2004). SNI 06-6989.11-2004 Air dan Air Limbah-Bagian 11: Cara uji derajat keasaman (pH) dengan menggunakan alat pH meter.

[14] Garg A., Aggarwal D., Garg S. dan Singla A.K. (2002). Spreading of semisolid formulations. Pharmaceutical technology, (September), 84-105.

[15] Darsana I.G.O. (2012). Potensi Daun Binahong (Anredera cordifolia (Tenore) Steenis) Dalam Menghambat Pertumbuhan Bakteri Escherichia coli Secara In Vitro. Indonesia Medicus Veterinus, 1 (3), 337-351.

[16] Maulina L. dan Sugihartini N. (2015) Formulasi Gel Ekstrak Etanol Kulit Buah Manggis (Garcinia mangostana L.) dengan Variasi Gelling Agnet Sebagai Sediaan Luka Bakar. Pharmaciana, 5 (1). p43.

[17] Ali S. dan Yosipovitch G. (2013). Skin pH: From Basic Science To Basic Skincare. Acta Dermatovenereologica. 93 (3). p261-267.

[18] Octavia D.R. (2009). Uji Aktivitas Penangkap Radikal Ekstrak Petroleum Eter, Etil Asetat dan Etanol Daun Binahong (Anredera cordifolia (Tenore) Steen) Dengan Metode DPPH (2,2-difenil-1-pikrihidrazil). Skripsi. Fakultas Farmasi, Universitas Muhammadiyah Surakarta, Surakarta.

[19] Departemen Kesehatan RI. (1995). Farmakope Indonesia, Edisi IV. Departemen Kesehatan RI, Jakarta.

[20] Nurahmanto D., Mahrifah I.R., Firda R., Imaniah N. dan Rosyidi V.A. (2017). Formulasi Sediaan Gel Dispersi Padat Ibuprofen : Studi Gelling Agent Dan Senyawa Peningkat. Ilmiah Manuntung, 3 (1). p96-105.

[21] Bochek A.M., Yusupova L.D., Zabivalova N.M. dan Petropavlovskii G.A. (2002). Rheological Properties of Aqueous H-Carboxymethyl Cellulose Solutions with Various Additives. 75 (4). p645-646.

[22] Shukr M.H. dan Metwally G.F. (2013). Evaluation of Topikal Gel Bases Formulated with Various Essential Oils for Antibacterial Activity against Methicillin-Resistant Staphylococcus aureus. Tropical Journal of Pharmaceutical Research, 12 (6). p111-114.

[23] Dwiastuti R. (2010). Pengaruh Penambahan CMC (Carboxymethyl Cellulose) Sebagai Gelling Agent dan Propilenglikol Sebagai Humektan dalam Sediaan Gel Sunscreen Ekstrak Kering Polifenol Teh Hijau (Camellia sinesis L.). Jurnal Penelitian, 3 (12). p227-240.

[24] Haque A.F. dan Sugihartini N. (2015). Evaluasi Uji Iritasi dan Uji Sifat Fisik Pada Sediaan Krim M/A Minyak Atsiri Bunga Cengkeh dengan Berbagai Variasi Konsentrasi. Pharmacy, 12 (2). p131-139.

[25] Lay B. (1994). Analisis Mikroba di Laboratorium. Rajawali Pers, Jakarta 